\title{
Synflorescence regeneration after cutting in Solidago xniederederi (Asteraceae), a hybrid between invasive $S$. canadensis and native $S$. virgaurea
}

\author{
Artur Pliszko ${ }^{1}$ (D) Justyna Pażucha ${ }^{1} \cdot$ Artur Górecki $^{1}$ (D) \\ Received: 15 June 2020 / Accepted: 15 October 2020 / Published online: 2 November 2020 \\ (C) The Author(s) 2020
}

\begin{abstract}
Solidago $\times$ niederederi, a natural hybrid between invasive $S$. canadensis and native $S$. virgaurea, is considered as naturalized alien taxon in Europe. In this study, we conducted a field experiment on the regeneration ability of $S$. ×niederederi after cutting off its synflorescences (panicles with capitula). The regeneration of synflorescences occurred in $79.6 \%$ of the examined shoots (ramets) of the hybrid. After regeneration shoots were significantly shorter and formed shorter, narrower and less branched synflorescences. Moreover, the number of capitula was significantly lower after regeneration as well as number of disc flowers and pollen viability. The obtained results suggest that the hybrid has a high ability of synflorescence regeneration after cutting and one-time cutting at high level during flowering is not effective method to control the hybrid in the wild.
\end{abstract}

Keywords Alien species $\cdot$ Mechanical damage $\cdot$ Plant hybridization $\cdot$ Pollen viability

\section{Introduction}

The ability of flower and inflorescence regeneration after mechanical damage of shoots can enhance naturalization and invasion of alien plants, especially in the case of species whose persistence in habitats relies crucially on seed production (no asexual reproduction ability). Regeneration of flowers and inflorescences can be easily observed in alien plants growing in anthropogenic (i.e., arable fields with cereals, lawns, roadsides, railway embankments, and flood banks) and semi-natural (meadows and grasslands) habitats, where the plant cover is subjected to the cutting. On the other hand, regular cutting (mowing or shredding) has been recommended to control many invasive plants (e.g., Pyšek et al. 2007; Bohren et al. 2008; Dudley et al. 2009; Simard and Benoit 2011; Tokarska-Guzik et al. 2011; Končeková et al. 2015; Monty et al. 2015; Lommen et al. 2018 and references therein). It is known that regeneration capability depends on the

Artur Pliszko

artur.pliszko@uj.edu.pl

1 Department of Taxonomy, Phytogeography, and Palaeobotany, Institute of Botany, Faculty of Biology, Jagiellonian University, Gronostajowa 3, 30-387 Kraków, Poland height, the timing and frequency of the cutting. For example, young individuals of invasive Ambrosia artemisiifolia L., which were cut just above a cotyledonary node, showed normal growth rate after two weeks from the cutting and about $50 \%$ of them started to flower (Tokarska-Guzik et al. 2011). However, the total number of seeds and their viability can be negatively affected by cutting treatments (Bohren et al. 2008; Lommen et al. 2018 and references therein).

Solidago $\times$ niederederi Khek (Asteraceae), a natural hybrid between the North American S. canadensis L. and the European S. virgaurea L. (Pliszko 2015; Pliszko and Zalewska-Gałosz 2016; Skokanová et al. 2020a), has been reported from 17 countries in Europe, including Austria, France, the United Kingdom, Denmark, Sweden, Norway, Finland, Italy, Germany, Hungary, Romania, Czechia, Slovakia, Poland, Lithuania, Latvia, and Russia (Jaźwa et al. 2018; Skokanová et al. 2020b). It is considered as naturalized alien taxon in Austria, Poland, Lithuania and Latvia (Gudžinskas and Petrulaitis 2016; Pliszko and Kostrakiewicz-Gierałt 2017; Pliszko et al. 2017). The hybrid occurs on abandoned fields, roadsides, railway embankments, in disused quarries and forest plantations, usually together with its parental species (Nilsson 1976; Pliszko and Kostrakiewicz-Gierałt 2017; Pliszko et al. 2017, 2019; Skokanová et al. 2020b). Solidago $\times$ niederederi is a perennial plant spreading by wind-dispersed fruits (cypselas). 
It forms clonal clusters of shoots (ramets) which can be composed of sexual shoots (shoots with capitula arranged in panicle synflorescence) or vegetative shoots (shoots with no capitula) or both sexual and vegetative shoots (Pliszko and Kostrakiewicz-Gieralt 2019). Seeds of the hybrid can achieve a high percentage of germination (more than $75 \%$ on average) with and without the involvement of cold stratification (Pliszko and Kostrakiewicz-Gierałt 2018a). However, the number of well-developed fruits is usually low in the hybrid (Migdałek et al. 2014).

Negative effects of $S$. canadensis invasion in Europe have been well documented and numerous methods of its control have been proposed (Kabuce and Priede 2010; Szymura and Szymura 2015; Szymura et al. 2016; Rajdus et al. 2020). Unfortunately, the studies on the impact of $S$. ×niederederi are neglected and so far, no attempt has been made to control the hybrid. Flowers of $S$. $\times$ niederederi are often visited by insects (Pliszko and Kostrakiewicz-Gierałt 2018b) and therefore it may pose a threat to native species by competition for pollinators. The risk of introgression with $S$. virgaurea is also highly probable since the hybrid is not fully sterile (Migdałek et al. 2014; Karpavičienè and Radušienè 2016) and usually both taxa occur in close proximity and their flowering periods overlap. Field observations made by the first author in Poland confirmed that invasive $S$. canadensis and native $S$. virgaurea can regrow and flower after mowing. Moreover, S. canadensis can regenerate from small fragments of underground rhizomes (Weber 2011). The regeneration capability of $S$. ×niederederi has not been intensively studied so far. As currently known, the hybrid does not produce long underground rhizomes which are found in S. canadensis (Pliszko and Kostrakiewicz-Gierałt 2017, 2019). However, resting buds located on the caudices of the hybrid can transform into new ramets after the mechanical division of the maternal cluster of ramets (Pliszko and Kostrakiewicz-Gierałt 2017). Furthermore, Pliszko et al. (2018) demonstrated that $S$. ×niederederi and its parental species can regenerate the roots and leaves from small fragments of aerial shoots. In this study, we aimed to test regeneration ability of $S$. ×niederederi after cutting off its synflorescences.

\section{Materials and methods}

\section{Field experiment}

The study was conducted on abandoned fields near Suwałki, north-eastern Poland (GPS coordinates: $54^{\circ} 06.050^{\prime} \mathrm{N}$, $22^{\circ} 53.062^{\prime}$ E, altitude: $173 \mathrm{~m}$ a.s.1.), in 2018. The study area is located in a temperate zone with an influence of the continental climate. In this place, the average annual air temperature is about $6{ }^{\circ} \mathrm{C}$ and the average annual precipitation is about $600 \mathrm{~mm}$ (Górniak 2000). The presence of Solidago $\times$ niederederi near Suwałki has been recently confirmed as a result of the ongoing invasion of $S$. canadensis in northeastern Poland (Pliszko et al. 2017). Ten clusters of $S$. $\times$ niederederi at peak flowering time (at least $75 \%$ of capitula was open in each ramet of the cluster) were randomly selected for the experiment, on 9 August 2018. The clusters consisted of 62 sexual ramets which were normally developed with no sign of mechanical damage within their synflorescences. The hybrid grew on dry-mesic sandy soil of 7.2-7.5 pH, in a fully light, and it was associated with its parental species as well as with meadow, xerothermic and segetal plant species of the classes Molinio-Arrhenatheretea, Festuco-Brometea, and Stellarietea mediae, respectively. The sexual ramets of the hybrid were marked with plastic labels and their length (the length of the shoot) was measured. Next, the synflorescences (panicles with capitula) of the selected ramets were cut off and collected. After 41 days the sexual ramets subjected to the experiment achieved peak flowering stage (at least $75 \%$ of capitula was open in each ramet of the regenerated cluster) and then they were cut off and collected. The level of shoot cutting was directly under the lowest secondary branch of the synflorescence. The development of capitula in selected clusters of ramets was simultaneous before and after regeneration. The synflorescences collected before and after regeneration were kept for 7 days at room temperature to dry. Three ramets of one cluster have been destroyed by animals and therefore they were excluded from further analysis. The ramets collected after the regeneration period were kept for 7 days at room temperature to dry. The hybrid was identified based on morphological features provided by Nilsson (1976) and Gudžinskas and Žalneravičius (2016).

\section{Biometric analysis}

The following features were included in the biometric analysis: the length of the shoot, the length and the width of the synflorescence, the number of secondary branches within the synflorescence, the number of capitula, and the number of ligulate and disc flowers per capitulum. The number of ligulate and disc flowers was tested in one randomly selected capitulum per shoot (ramet). The measurement of morphological features was made on dry materials.

\section{Estimation of pollen viability (stainability)}

Pollen study was conducted using dry synflorescences which were kept for one year at room temperature. Dry pollen was obtained from one disc flower from random capitulum per each ramet. In total, pollen from 36 disc flowers for each group was examined. Pollen grains were separated from anthers and put on slides with drops of $1 \%$ acetocarmine (on average $37 \pm 23$ pollen grains per slide). Viable pollen cytoplasm stains red, while nonviable pollen remains unstained (Migdałek et al. 2014). The viability of pollen was assessed in 3 random fields of view 
under $160 \times$ magnification (Field of view Diameter DFV = $96.88 \mu \mathrm{m})$, using an optical microscope.

\section{Data analysis}

To compare differences in measured features before and after synflorescence regeneration, paired sampled tests were used. Normality was checked using the Shapiro-Wilk test. Differences in synflorescence length, shoot length, amount of disc flowers per capitulum, the number of capitula per ramet and percentage of viable pollen were tested using the Wilcoxon signed-rank test due to abnormal distribution. Respectively comparison of the amount of all flowers per capitulum, amount

Fig. 1 Results of biometric analysis (a-h) and pollen viability test (i). Boxes - median with Interquartile Range (IQR), whiskers - min-max values
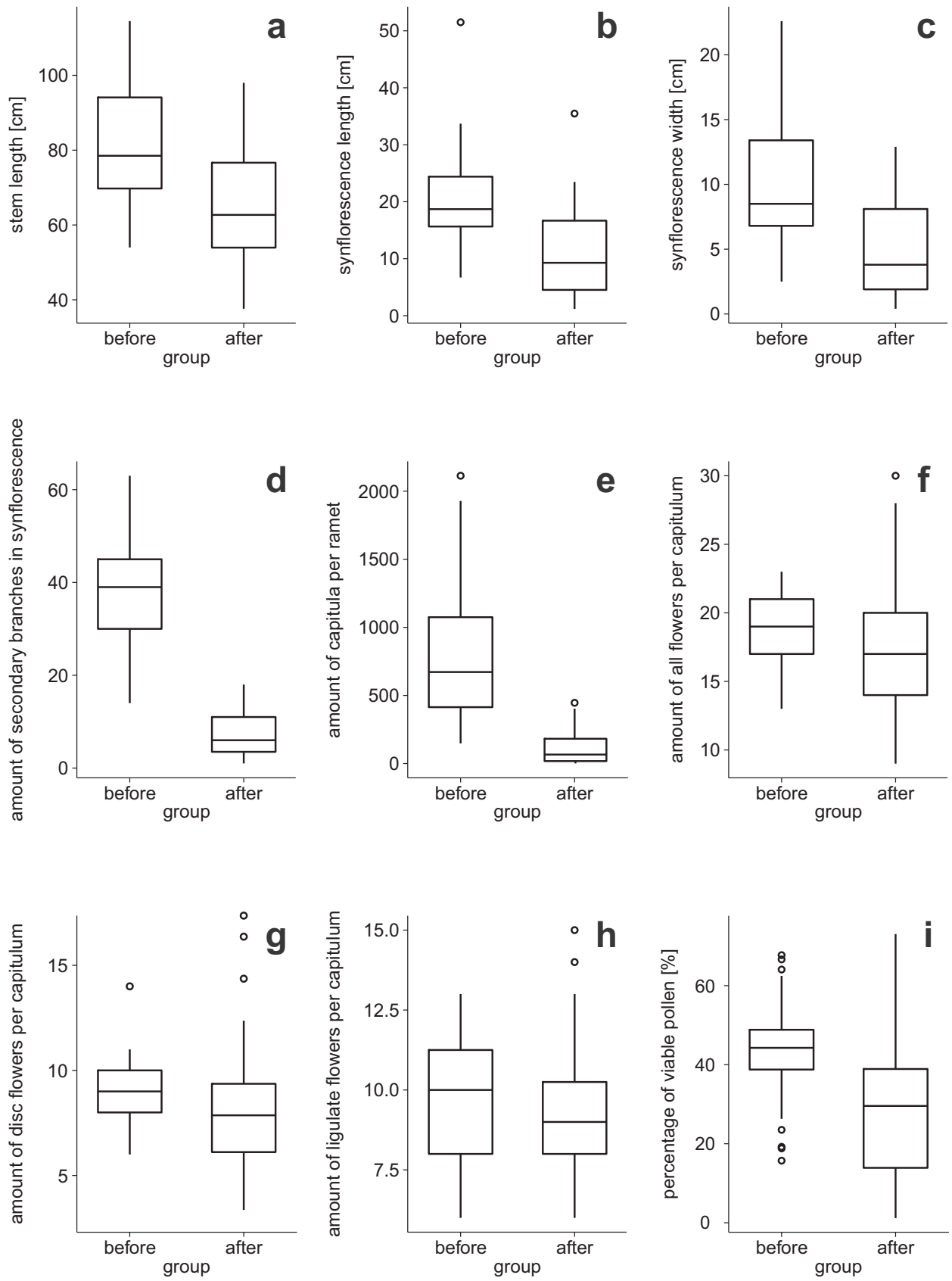
forming shorter, narrower and less branched synflorescences (Fig. 1b, $V=1090, p<0.01$; Fig. $1 \mathrm{c}, t=9.3, d f=46, p<0.01$; Fig. $1 \mathrm{~d}, t=20.3, d f=46, p<0.01$, respectively). Moreover, the number of capitula was significantly lower after regeneration (Fig. 1 e, $V=1128, p<0.01$ ). In regenerated synflorescences capitula had significantly less flowers (Fig. 1f, $t=2.5, d f=39, p=0.02$ ), although regeneration affected directly only the abundance of disc flowers (Fig. 1g, $V=$ 485.5, $p=0.01$ ), not ligulate flowers (Fig. $1 \mathrm{~h}, t=0.9, d f=39$, $p=0.35$ ). Pollen developed before regeneration was characterized by rather low viability (Fig. 1i). After regeneration it was significantly lowered $(V=87, p<0.01)$, in some cases not even $10 \%$ of pollen was stained.

Our study revealed that $S$. $\times$ niederederi has a high ability of synflorescence regeneration after cutting. However, the hybrid is not able to form synflorescences whose size would be comparable to the size before their mechanical damage. Reduced size of synflorescence in regenerated plants was also observed in Ambrosia artemisiifolia after mowing. In mowed and dense stands of this species male synflorescences were 35 times shorter than those in intact and single plants (Simard and Benoit 2011). Interestingly, in the case of Erigeron annuus, the number of regenerated capitula can be influenced by altitude. Trtikova (2009) proved that individuals of E. annuus growing at $400 \mathrm{~m}$ a.s.l. formed more capitula after cutting than individuals not subjected to the cutting. On the other hand, individuals growing at $>1000 \mathrm{~m}$ a.s.l. had fewer capitula after cutting than individuals not subjected to the cutting. The effects of plant density and altitude and other environmental factors on synflorescence regeneration in $S$. $\times$ niederederi should be tested in the future.

The synflorescence regeneration negatively affects pollen viability in $S$. $\times$ niedereder $i$ and in consequence, it may lead to reduced seed production $\left(\mathrm{F}_{2}\right.$ generation). Also, the number of disc flowers, which produce the pollen, is lower in regenerated plants. Normally the hybrid has reduced pollen viability (Migdałek et al. 2014) and after cutting the pollen viability can be even more reduced. Studies on A. artemisiifolia showed that plants regenerated after mowing produce much less pollen and seeds than those which have not been damaged and the shorter the male synflorescence, the less pollen the flowers produce (Simard and Benoit 2011). Moreover, the anthesis was delayed by 17 days by the mowing treatment and the seeds of mown plants were less viable in A. artemisiifolia (Simard and Benoit 2011).

According to Pliszko and Kostrakiewicz-Gierałt (2018b), $S$. $\times$ niederederi attracts many insects (including pollinators) and the number of insect visits is positively correlated with the size of synflorescence and number of capitula. This suggests that reduced size of synflorescence and a low number of capitula after regeneration may limit the competitiveness of the hybrid for pollinators. However, a low number of capitula with a low number of flowers with a low number of viable pollen in the hybrid does not eliminate the risk of introgression with $S$. virgaurea. The removal of invasive Solidago L. species is a time consuming and costly process (Szymura et al. 2016). To prevent the negative effects of hybridization and introgression with native species, $S$. canadensis and $S$. $\times$ niederederi should be removed from habitats occupied by $S$. virgaurea as fast as possible. Our study suggests that onetime cutting at high level of the shoots during flowering is not effective method and it cannot be recommended to control the hybrid in the wild. It is important to establish the height, the frequency, and timing of the cutting in further studies. Moreover, chemical, biological and complex treatments should be also involved as in the case of $S$. canadensis (Kabuce and Priede 2010; Rajdus et al. 2020).

Acknowledgments The authors would like to thank the Reviewers for their valuable comments and suggestions and Professor Marzena Popielarska-Konieczna (Department of Plant Cytology and Embryology, Institute of Botany, Jagiellonian University) for providing acetocarmine for pollen viability test.

Authors' contributions AP - research conceptualization, sample design and methodology, investigation and data collection, data analysis and interpretation, manuscript writing and editing; JP - investigation and data collection, data analysis and interpretation, manuscript writing and editing; AG - data collection, data analysis and interpretation, manuscript writing and editing.

Funding The collection and analysis of data and the preparation of the manuscript were financially supported by the Institute of Botany of the Jagiellonian University in Krakow (K/ZDS/008058).

\section{Compliance with ethical standards}

Conflict of interest The authors declare that they have no conflict of interest.

Open Access This article is licensed under a Creative Commons Attribution 4.0 International License, which permits use, sharing, adaptation, distribution and reproduction in any medium or format, as long as you give appropriate credit to the original author(s) and the source, provide a link to the Creative Commons licence, and indicate if changes were made. The images or other third party material in this article are included in the article's Creative Commons licence, unless indicated otherwise in a credit line to the material. If material is not included in the article's Creative Commons licence and your intended use is not permitted by statutory regulation or exceeds the permitted use, you will need to obtain permission directly from the copyright holder. To view a copy of this licence, visit http://creativecommons.org/licenses/by/4.0/.

\section{References}

Bohren C, Delabays N, Mermillod G, Baker A, Vertenten J (2008) Ambrosia artemisiifolia L.: Optimieren des Schnittregimes. Agrarforschung 15:308-313

Dudley MP, Parrish JAD, Post SL, Helm CG, Wiedenmann RN (2009) The effects of fertilization and time of cutting on regeneration and 
seed production of Dipsacus laciniatus (Dipsacaceae). Nat Areas J 29:140-145. https://doi.org/10.3375/043.029.0206

Górniak A (2000) Klimat województwa podlaskiego. IMiGW, Białystok Gudžinskas Z, Petrulaitis L (2016) New alien plant species recorded in the southern regions of Latvia. Bot Lith 22:153-160. https://doi.org/ 10.1515/botlit-2016-0016

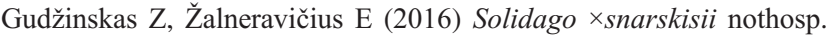
Nov. (Asteraceae) from Lithuania and its position in the infrageneric classification of the genus. Phytotaxa 253:147-155. https://doi.org/ 10.11646/phytotaxa.253.2.4

Jaźwa M, Jędrzejczak E, Klichowska E, Pliszko A (2018) Predicting the potential distribution area of Solidago $\times$ niederederi (Asteraceae). Turk J Bot 42:51-56. https://doi.org/10.3906/bot-1703-17

Kabuce N, Priede N (2010) NOBANIS - Invasive Alien Species Fact Sheet - Solidago canadensis. Online Database of the European Network on Invasive Alien Species - NOBANIS. https://www. nobanis.org. Accessed 25 Oct 2019

Karpavičienė B, Radušiene J (2016) Morphological and anatomical characterization of Solidago $\times$ niederederi and other sympatric Solidago species. Weed Sci 64:61-70. https://doi.org/10.1614/WS-D-1500066.1

Kassambara A (2019) Ggpubr:'Ggplot2’Based Publication Ready Plots, R Package Version 0.2

Končeková L, Zahradníková E, Pintér E, Halmová D (2015) Assessment of an impact of mechanical regulation on selected morphometric and productive parameters of invasive species Solidago canadensis population in agricultural land. Agriculture (Pol'nohospodárstvo) 61: 121-128. https://doi.org/10.1515/agri-2015-0017

Lommen STE, Jongejans E, Leitsch-Vitalos M, Tokarska-Guzik B, Zalai M, Müller-Schärer H, Karrer G (2018) Time to cut: population models reveal how to mow invasive common ragweed cost-effectively. NeoBiota 39:53-78. https://doi.org/10.3897/neobiota.39. 23398

Migdałek G, Kolczyk J, Pliszko A, Kościńska-Pająk M, Słomka A (2014) Reduced pollen viability and achene development in Solidago $\times$ niederederi Khek from Poland. Acta Soc Bot Pol 83:251-255. https://doi.org/10.5586/asbp.2014.025

Monty A, Eugène M, Mahy G (2015) Vegetative regeneration capacities of five ornamental plant invaders after shredding. Environ Manag 55:423-430. https://doi.org/10.1007/s00267-014-0398-4

Nilsson A (1976) Spontana gullrishybrider (Solidago canadensis $\times$ virgaurea) i Sverige och Danmark. Sven Bot Tidskr 70:7-16

Pliszko A (2015) Neotypification of Solidago $\times$ niederederi (Asteraceae). Phytotaxa 230:297-298. https://doi.org/10.11646/phytotaxa.230.3. 10

Pliszko A, Kostrakiewicz-Gierałt K (2017) Resolving the naturalization strategy of Solidago $\times$ niederederi (Asteraceae) by the production of generative ramets and seedlings. Plant Ecol 218:1243-1253. https:// doi.org/10.1007/s11258-017-0762-6

Pliszko A, Kostrakiewicz-Gierałt K (2018a) Effect of cold stratification on seed germination in Solidago $\times$ niederederi (Asteraceae) and its parental species. Biologia 73:945-950. https://doi.org/10.2478/ s11756-018-0113-7

Pliszko A, Kostrakiewicz-Gierałt K (2018b) Flower-visiting insects on Solidago $\times$ niederederi (Asteraceae): an observation from a domestic garden. Botanica 24(2):162-171. https://doi.org/10.2478/botlit2018-0016

Pliszko A, Kostrakiewicz-Gierałt K (2019) The importance of sexual, asexual and mixed ramet clusters in production of descendant ramets in populations of Solidago $\times$ niederederi (Asteraceae). Biologia 74(8):953-960. https://doi.org/10.2478/s11756-019-00233-y

Pliszko A, Zalewska-Gałosz J (2016) Molecular evidence for hybridization between invasive Solidago canadensis and native $S$. virgaurea. Biol Invasions 18:3103-3108. https://doi.org/10.1007/s10530-0161213-3
Pliszko A, Łazarski G, Kalinowski P, Adamowski W, Rutkowski L, Puchałka R (2017) An updated distribution of Solidago $\times$ niederederi (Asteraceae) in Poland. Acta Mus Siles Sci Natur 66(3):253-258. https://doi.org/10.1515/cszma-2017-0026

Pliszko A, Kostrakiewicz-Gierałt K, Wójcik T (2018) Regeneration ability from shoot fragments in Solidago $\times$ niederederi (Asteraceae) and its parental species. In: $27^{\text {th }}$ Congress of the European Vegetation Survey 23-26 May, 2018, Wrocław, Poland. Vegetation survey 90 years after the publication of Braun-Blanquet's textbook - new challenges and concepts. Book of Abstracts. Sabat-Studio Graficzne, Wrocław, pp. 144

Pliszko A, Adamowski W, Pagitz K (2019) New distribution records of Solidago $\times$ niederederi (Asteraceae) in Austria, Italy, and Poland. Acta Mus Siles Sci Natur 68:195-199. https://doi.org/10.2478/ cszma-2019-0020

Pyšek P, Perglová I, Krinke L, Jarošík V, Pergl J, Moravcová L (2007) Regeneration ability of Heracleum mantegazzianum and implications for control. In: Pyšek P, Cock MJW, Nentwig W, Ravn HP (eds) Ecology \& Management of Giant hogweed (Heracleum mantegazzianum). CAB International, Wallingford, pp 112-125

R Core Team (2015) R: a language and environment for statistical computing. R Foundation for Statistical Computing, Vienna

Rajdus T, Švehláková H, Plohák P, Stalmachova B (2020) Management of invasive Solidago canadensis in Ostrava region (Czech Republic). IOP Conf Ser: Earth Environ Sci 444:012046. https://doi.org/10.1088/1755-1315/444/1/012046

RStudio Team (2015) RStudio: integrated development for R. RStudio, Inc., Boston

Simard MJ, Benoit DL (2011) Effect of repetitive mowing on common ragweed (Ambrosia artemisiifolia L.) pollen and seed production. Ann Agr Env Med 18:55-62

Skokanová K, Mered’a P, Šingliarov B, Španiel S (2020a) Lectotype of Solidago $\times$ niederederi (Asteraceae) selected from recently rediscovered original material. Phytotaxa 438:62-64. https://doi. org/10.11646/phytotaxa.438.1.8

Skokanová K, Šingliarová B, Španiel S, Hodálová I, Mered’a Jr. P (2020b) Tracking the expanding distribution of Solidago $\times$ niederederi (Asteraceae) in Europe and first records from three countries within the Carpathian region. BioInvasions Records 9 (in press)

Szymura M, Szymura TH (2015) Growth, phenology, and biomass allocation of alien Solidago species in Central Europe. Plant Spec Biol 30:245-256. https://doi.org/10.1111/1442-1984.12059

Szymura M, Szymura TH, Wolski K (2016) Invasive Solidago species: how large area do they occupy and what would be the cost of their removal. Pol J Ecol 64:25-34. https://doi.org/10.3161/ 15052249PJE2016.64.1.003

Tokarska-Guzik B, Bzdęga K, Koszela K, Żabińska I, Krzuś B, Sajan M, Sendek A (2011) Allergenic invasive plant Ambrosia artemisiifolia L. in Poland: threat and selected aspects of biology. Biodiv Res Conserv 21:39-48. https://doi.org/10.2478/v10119-011-0008-8

Trtikova M (2009) Effects of competition and mowing on growth and reproduction of the invasive plant Erigeron annuus at two contrasting altitudes. Bot Helv 119:1-6. https://doi.org/10.1007/s00035009-0050-8

Weber E (2011) Strong regeneration ability from rhizome fragments in two invasive clonal plants (Solidago canadensis and S. gigantea). Biol Invasions 13:2947-2955. https://doi.org/10.1007/s10530-0119977-y

Publisher's note Springer Nature remains neutral with regard to jurisdictional claims in published maps and institutional affiliations. 